\title{
NASKAH SAJARAH CIREBON: TRANSLITERASI DAN ANALISIS NILAI MORAL
}

\author{
Ai Hayati Mayang Arum \\ MGMP Bahasa Sunda Kota Bandung \\ Pos-el: hayatimayang_arum@yahoo.com
}

\begin{abstract}
Abstrak
Penelitian ini bertujuan untuk mengetahui isi teks dalam naskah Sejarah Cirebon, mengidentifikasi keadaan dan asal-muasal naskah, nyusun transliterasi dan menganalisis nilai moral yang terkandung di dalamnya. Dengan begitu, metode yang digunakan dalam penelitian ini adalah metode filologi edisi naskah tunggal, sedangkan analisis strukturnya menggunakan metode deskriptif-analitis. Adapun langkah-langkah yang dilaksanakannya yaitu 1) deskripsi naskah, 2) transliterasi teks, 3) analisis teks. Naskah yang dijadikan bahan penelitian ini ditulis dalam huruf Pegon. Naskah ini merupakan koleksi pribadi almarhum Aki Yahya Permana, dari Panawangan-Ciamis. Bentuknya wawacan, dan ukuran naskahnya adalah $16,5 \times 21,5 \times 2,5 \mathrm{~cm}$. Dari hasil penelitian ini ditemukan 1) deskripsi naskah sajarah cirebon 2) transliterasi naskah sajarah cirebon 3) ajén moral dina naskah sajarah cirebon. Nilai-nilai moral yang dapat diaplikasikan dalam kehidupan seharihari, yaitu 1) nilai moral manusia pada Tuhan, 2) nilai moral manusia pada dirinya, 3) nilai moral manusia pada manusia lainnya 4) nilai moral manusia pada alam, 5) nilai moral manusia terhada waktu, 6) nilai moral manusia dalam mencapai kepuasan lahiriah dan batiniah.
\end{abstract}

Kata kunci: transliterasi, naskah, nilai moral.

\section{CIREBON MANUSCRIPT HISTORY: THE TRANSLITERATION AND THE ANALYSIS OF MORAL VALUES}

\begin{abstract}
This study was aimed to determine the contents of the text in the Cirebon manuscript history, identify the circumstances and the origin of the text, arrange transliteration and analyze the moral values contained in it. That way, the method used in this study is a single manuscript edition method of philology, while the structure analysis used descriptiveanalytical methods. The steps carried out were 1) text description, 2) text transliteration, 3) text analysis. The manuscript was employed as material for this research was written in Pegon's letter. This text is a private collection of the late Aki Yahya Permana, from Panawangan-Ciamis. The script form is wawacan, and its size of is $16.5 \mathrm{~cm} \times 21.5 \mathrm{~cm} x$ $2.5 \mathrm{~cm}$. The results of this study found the following results:1) the description Cirebon manuscript history 2) the transliteration of Cirebon manuscript history 3) the moral doctrine and Cirebon manuscript history. Moral values that can be implemented in everyday life, i.e. 1) human moral values to God, 2) human moral values to themselves, 3) human moral values to other humans, 4) human moral values to nature, 5) human moral values to time, 6) human moral values in achieving satisfaction outwardly and inwardly.
\end{abstract}

Keywords: transliteration, manuscripts, moral values 


\section{PENDAHULUAN}

Filologi yaitu ilmu yang berkaitan langsung dengan memelihara dan melestarikan budaya. Filologi juga merupakan cabang ilmu pengetahuan yang di dalamnya meliputi bidang sastra, bahasa dan budaya. Hal ini diungkapkan dalam Fathurahman (2015, hal. 12), yang menyebutkan bahwa filologi yaitu ilmu mengenai bahasa, kebudayaan, pranata dan sejarah bangsa. Secara etimologis, asal kata filologi yaitu dari philologia, serta dibangun oleh dua kata yaitu: philoslogos. Philos artinya yang tercinta (affertion, loved, beloved, dear, friend) dan logos artinya kata, artikulasi, alasan, (word, articulation, reason).

Hal ini sependapat dengan Djamaris dalam Said (2016. hal. 205), yang menyebutkan bahwa asal kata filologi dari bahasa Latin, yaitu Philos yang berarti cinta dan Logos yang berarti ilmu.

Naskah merupakan salah satu sumber primer paling otentik yang bisa mendekatkan antara jaman dahulu dan jaman sekarang. Naskah merupakan jalan untuk menambah pengetahuan dan sejarah sosial kehidupan masyarakat jaman dahulu, asalkan tahu cara membaca dan menafsirkannya (Fathurahman, 2015 hal. 27).

Dalam (Isyanti, 2013, hal.1) dijelaskan bahwa naskah atau manuskrip merupakan rekaman informasi tertulis atau karya tulis yang dihasilkan sebagai produk kegiatan manusia, yang merekam informasi, diantaranya buah pemikiran, perasaan, kepercayaan, adat kebiasaan, dan nilai-nilai yang dipakai dikalangan masyarakat tertentu. Menurut Baried (1985, hal.4), naskah merupakan objek kajian penelitian filologi, yang tujuannya untuk mengenalkan suatu naskah dengan sempurna, agar bisa memahami isi dan makna dari naskah tersebut, serta mengungkapkan budaya-budaya terdahulu untuk perkembangan budaya jaman sekarang. Selain itu, tujuan khususnya yaitu untuk menyusun edisi teks yang dianggap paling dekat dengan teks aslinya, mengungkap sejarah adanya teks, sejarah perkembangannya, serta mengungkapkan resepsi pada setiap jangka waktu penerima.

Menurut Purnomo dalam Antoni (2016, kc. 120), disebutkan bahwa Naskah kuno atau manuskrip merupakan dokumen dari berbagai macam jenis yang ditulis dengan tangan tetapi lebih mengkhususkan kepada bentuk yang asli sebelum dicetak.

Naskah mempunyai akar kata dari bahasa Arab (al nuskhah) yang merupakan padanan kata bahasa Indonesia yaitu manuskrip. Dalam Kamus Besar Bahasa Indonesia (KBBI) kata naskah diartikan sebagai karangan yang masih ditulis tangan. Naskah merupakan bentuk fisik dokumen. Dokumendokumen kuno tersebut bisa sampai kepada masyarakat jaman sekarang, setelah mengalami beberapa salinan. Tulisan ini ditulis menggunakan tangan serta menggunakan bahan-bahan dan media tulis yang alami. Tulisan tersebut sampai kepada masyarakat jaman sekarang, dan biasa disebut dengan istilah "naskah kuno".

Naskah merupakan objek kajian filologis. Menurut Suryani (2010, hal. 122), objek penelitian filologi yaitu tulisan tangan yang menyimpan banyak ungkapan, pikiran, dan perasaan, sebagai hasil budaya bangsa jaman dahulu. Semua bahan tulisan tangan itu disebut naskah handsscrift. Oleh karena itu naskah merupakan barang nyata yang bisa dilihat atau dipegang, sedangkan teks yaitu kandungan atau isi dari naskah yang sifatnya abstrak.

Isi naskah salah satunya merupakan bentuk cerita, dan ada yang dalam bentuk wawacan. Terkait dengan pengertian wawacan, Koswara (2013, hal. 82), menjelaskan bahwa wawacan merupakan cerita panjang yang dibuat 
dengan aturan pupuh. Jalan ceritanya banyak bagian-bagiannya. Hal ini sama dengan pendapat Ruhaliah (2013, kc. 2), yang menjelaskan bahwa wawacan merupakan karya sastra naratif yang disusun dalam bentuk pupuh. Meskipun wawacan bukan merupakan kesusastraaan asli Sunda, akan tetapi banyak ditemukan dalam naskah-naskah Sunda. Hal ini berhubungan dengan pengaruh kesusastraan Jawa yang masuk ke tatar Sunda melewati para menak dan pesantren. Tulisannya ada yang memakai aksara Jawa (Cacarakan), ada juga yang menggunakan aksara Pegon.

Naskah kuno yang tulisan dan bahasanya menggunakan bahasa dan aksara Sunda kuno, aksara Pegon, Cacarakan, dan lain sebagainya sering menjadi keluhan bagi masyarakat. Oleh karena itu, akademisi dan orang yang bisa membaca naskah mempunyai tanggung jawab untuk mengadakan penelitian berupa transliterasi dari naskah tersebut, agar bisa dipahami oleh masyarakat serta dapat dirasakan manfaatnya. Baried (1985, kc. 65) menjelaskan, transliterasi artinya bergantinya jenis tulisan, aksara per aksara, dari huruf yang satu ke huruf yang lainnya. Istilah ini dipakai bersamaan dengan istilah transkripsi serta pengertain yang sama terhadap bergantinya jenis tulisan naskah. Digantinya jenis tulisan dalam prasasti umumnya disebut transkripsi. Jika transkripsi dibedakan dengan transliterasi, transkripsi merupakan salinan atau turunan tanpa mengganti jenis tulisan (hurufnya sama).

Transliterasi merupakan hal yang penting dalam kehidupan manusia yang "berbudaya". Transliterasi dianggap perlu karena tansliterasi merupakan salah satu usaha untuk menyelamatkan isi dari teks naskah lama agar bisa dipahami manfaatnya oleh masyarakat. Transliterasi dapat diartikan juga sebagai salah satu upaya untuk menumbuhkan minat baca masyarakat terhadap naskah lama, dan diharapkan akan adahikmah serta manfaatnya, meskipun hanya bercermin dari masa lalu.

Naskah dan transliterasi merupakan dua sisi yang sulit dipisahkan, melalui proses transliterasi ini, akan mengetahui semua jenis isi dalam naskah tersebut. Salah satunya akan tahu mengenai nilai apa yang terdapat dalam naskah tersebut.

Moral atau sikap yaitu hal yang sifatnya positif menurut manusia lainnya, moral mutlak harus dimiliki oleh semua orang sebab, orang yang bermoral akan diterima dan dihargai di lingkungan masyarakatnya, mempunyai karakter, taat terhadap seluruh aturan dan tidak egois. Begitupun dengan orang Sunda, sebagai penduduk yang jumlah penduduknya kedua terbesar di Indonesia, mempunyai nilai-nilai dan karakter yang harus diterapkan dalam kehidupan sehari-hari.

Sudaryat (2014, hal. 125-127), menjelaskan bahwa nilai yang menjadi pandangan hidup orang Sunda yaitu (1) moral manusia terhadap Tuhannya (2) moral manusia terhadap dirinya sendiri (3) moral manusia terhadap manusia lainnya (4) moral manusia terhadap alam, (5) moral manusia terhadap waktu, dan (6)moral manusia dalam mengejar kepuasan lahiriah dan batiniahnya.Untuk mencapai manusia Sunda yang bermoral harus didasarioleh etnapedagogik Sunda yang disebut denganPanca Pancawaluya (gerbang lima kesempurnaan) yaitu: cageur, bageur, bener, pinter tur singer.

\section{METODE}

Métode yaitu cara atau sistem kerja. Métodologidisebut juga sebagai pengetahuan mengenai hal-hal yang merupakan cara untuk menerangkan mengenai variabel konsep atau definisi konsep yang berhubungan, serta mencari konsep secara empiris. Oleh karena itu, metode yang digunakan dalam penelitian ini yaitu metode filologi yang merupakan pengetahuan mengenai cara, teknik, atau instrument yang dilakukan dalam penelitian filologi. Penelitian ini menggunakan metode filologi edisi 
naskah tunggal, sedangkan analisis strukturnya menggunakan metode deskriptif-analitis.

Pengertian metode penelitian
dijelaskan oleh beberapa ahli,
diantaranya, metode penelitian merupakan suatu proses yang sistematik berdasarkan prinsip dan tekhnik ilmiah yang dipakai untuk mencapai suatu tujuan tertentu (Noor, 2015, hal. 22). Metode deskriptif-analitis menurut Ratna (2011, kc. 53), yaitu metode penelitian yang mendeskripsikan fakta-faktanya lalu disusul dengan analisisnya.

\section{HASIL DAN PEMBAHASAN Deskripsi Naskah Sajarah Cirebon}

Naskah yang dijadikan bahan penelitian yaitu naskah Sejarah Cirebon, ditulis dalam aksara Pegon. Naskah ini merupakan koleksi pribadi dari almarhum Aki Yahya Permana, dari Panawangan Ciamis, serta merupakan naskah salinan yang ditulis langsung oleh Aki Yahya. Dalam naskah ini terdapat kolofon yang menyebutkan waktu dan tempat disalinnya naskah, yaitu tahun 19821984. Serta disebutkan judul, nama dan alamat yang menyalin, yaitu Yahya Permana, Kampung Salam.

Naskah Sajarah Cirebon merupakan salah satu judul dari satu nuku naskah. Bentuknya wawacan, dengan tebal 133 lembar dan 16 halaman, bahan naskah dari kertas pabrik, ditulis oleh mangsi biasa. Jumlah pupuhnya ada 10pupuh dan 1019 bait.

Fungsi naskah dulunya, hanya sebagai koleksi pribadi. Dibaca ketika Aki Yahya ingin menghafal lagi sejarahnya, atau ketika mendongeng pada anak cucunya. Selain itu naskah ini dianggap sakral sebab sering dirawat dan disebut kitab, serta tidak boleh dibuka sembarangan. Disimpan di tempat yang bersih, menggunakan kamper atau bubuk kemenyan. Tidak boleh di foto kopi atau dipinjamkan. Sedangkan fungsinya sekarang yaitu masih sebaga kitab sejarah. Suka dibaca ketika santai, tidak boleh di foto kopi, dipinjamkan dan kalau membaca harus berhati-hati.

Dalam Naskah Sajarah Cirebon terdiri dari Pupuh Dangdanggula, Pupuh Kinanti, Pupuh Asmarandana, Pupuh Magatru, Pupuh Pucung, Pupuh Mijil, Pupuh Sinom, Pupuh Maskumambang, Pupuh Pangkur dan Pupuh Durma. Frekuensinya pupuh Dangdanggula lima kali, Pupuh Kinanti lima kali, Pupuh Asmarandana empat kali, Pupuh Magatru satu kali, Pupuh Pucung tiga kali, Pupuh Mijil dua kali, Pupuh Sinom tiga kali, Pupuh Maskumambang satu kali, Pupuh Pangkur satu kali, Pupuh Durma satu kali.

Pupuh Dangdanggula dan Pupuh Kinanti frekuensinya dipakai lebih banyak daripada pupuh-pupuh yang lainnya. Pupuh Dangdanggula dan Pupuh Kinanti lebih banyak digunakan sebab isi naskah lebih banyak menceritakan mengenai keagungan ilmu yang luhur serta tabiat para wali. Begitu juga banyak cerita hal-hal yang sifatnya menunggu. Contohnya menceritakan yang sedang bertapa, menceritakan yang sedang ditinggalkan oleh orang yang sedang berkelana, dan sebagainya.

\section{Transliterasi Naskah Sejarah Cirebon}

Isi naskah Sajarah Cirebon menceritakan tentang perjalanan Putra Siliwangi, yaitu Walangsungsang dan Rarasantang yang pergi dari Negara karena ingin berguru ilmu Agama Islam. Walangsungsang mengajak bapaknya masuk Islam tapi malah diusir dari Negara, tidak lama Rarasantang adiknya menyusul.

Walangsungsang dan Rarasantang berkelana, mencari ilmu agama. Menelusuri gunung-gunung, berguru kepada setiap orang. Keduanya berkelana, ada kalanya berbarengan dan ada kalanya berpisah. Adapun yang dicarinya yaitu ilmu agama mengenai syahadat serta ingin bertemu dengan Nabi Muhammad. 
Walasungsang gurunya banyak sekali, sampai ada gurunya yang menyuruh membuat pedukuhan di daerah Panjunan. Pekerjaannya bertapa dan membuat terasi.

Suatu waktu Walangsungsang dan Rarasantang naik haji ke Mekah. Di Mekah Rarasantang mendapatkan jodoh kepada Raja Mesir, yang baru ditinggalkan wafat oleh istrinya.

Sesudah Rarasantang menikah, Walasungsang kembali lagi ke Jawa serta meneruskan berkelana. Berguru sambil menyebarkan agama Islam.

Diceritakan Rarasantang ketika hamil sembilan bulan suaminya meninggal, tidak lama lahirlah bayi kembar, yaitu Seh Sarip Hidayat dan Seh Aripin. Sarip Aripin dan Sarip Hidayat rajin belajar ilmu agama. Tapi Sarip Hidayat ada lebihnya. Sampai mendapatkan petunjuk, dan bermimpi bertemu dengan Nabi Muhammad serta harus dicarinya.

Sarip Hidayat memilih mencari ilmu agama dan mencari Kanjeng Nabi. Sarip Aripin mengganti bapaknya menjadi Raja Mesir. Sarip Hidayat berkelana sampai ke Jawa. Serta berpengalaman berguru ke setiap orang sakti dan pedeta. Sering bertapa dimana-mana. Sampai suatu waktu sampai ke negri jin dan berpengalaman mi'roj ke tujuh lapis langit.

Di setiap langit bertemu dengan ahli surga termasuk para Nabi dan malaikat. Di langit ke tujuh Sarip Hidayat bertemu dengan Kanjeng Rosul serta diajarkan syahadat sejati.

Sesudah mi'roj Sarip Hidayat pergi ke Pulo Jawa. Mendatangi pendeta-pendeta yang akan menjadi calon wali agar rajin belajar ilmu agama. Sambil menyebarluaskan ilmu mengenai keagamaan, orang-orang yang didatangi semua disuruh guru ke Gunung Jati.

Sarip Hidayat berkelana menelusuri jagat raya dan sampai ke negri Cina dan bermukim di sana sebagai dukun dan menyembuhkan banyak orang.
Karena di negri Cina ketika itu sedang terserang penyakit. Sampai mengalami diuji raja Cina, agar menebak isi kandungan putrinya, yang sebenarnya hanya bokor yang dimasukkan. Tapi Sarip Hidayat menyebutkan bahwa bokor itu benar serta anak dalam kandungannya perempuan. Ternyata hal itu menjadi kenyataan serta raja Cina merasa heran.

Suatu waktu Sarip datang ke Negara Mesir bertemu adiknya yang sudah jadi Raja. Adiknya akan menyerahkan kekuasaan kepada kakaknya, karena yang lebih berhak yaitu Sarip Hidayat. Tetapi Sarip Hidayat tidak menerimanya karena dia hanya ingin menjadi ahli ilmu agama serta lebih memilih tinggal di Jawa menjadi Ratuning Wali. Sarip Hidayat hanya meminta putrinya Sarip Aripin untuk diajak ke Jawa serta berdiam dengannya. Oleh adiknya diizinkan putrinya dipasrahkan kemudian dibawa ke Jawa oleh Sarip Hidayat.

Indang Geulis, istri dari Rarasantang yang ada di Panjunan sudah mempunyai putra, bernama Pakungwati. Serta akan pergi ke Gunung Jati bertemu wali, yaitu Seh Sarip Hidayat untuk berguru ilmu karena diamanahi oleh suaminya, Walangsungsang alias Kuwu Sangkan.

Di Gunung Jati, Sarip Hidayat kedatangan para pengagung dari manamana yang ingin berguru. Semuanya tertarik dengan ilmu syahadat yang dimiliki Sarip Hidayat.

$\begin{array}{lcr}\text { Cerita } & \text { kaselang } & \text { dengan } \\ \text { menceritakan } & \text { Raden Sahid yang } \\ \text { ditinggalkan mati oleh ayahnya, }\end{array}$ Tumenggung Tuban. Sahid mempunyai maksud menjual Negara dan dibeli oleh patihnya. Sahid berkelana mencari ilmu agama. Akhirnya dia menjadi wali. Sembari menyebarkan agama Islam dengan Sarip Hidayat.

Sampai suatu waktu para wali menyebarkan agama Islamnya sudah sangat luas, yang belum masuk agama Islam adalah kerajaan Majapahit, Prabu 
Brawijaya tidak mau menganut agama Islam. Oleh karena itu, para wali bermaksud akan menyerang kerajaan Majapahit agar bisa takluk dan mau masuk agama Islam.

Peperangan dimulai, pasukan Islam kalah, sampai akhirnya yang maju jadi kepala perang yaitu Raden Patah, sebagai anak Brawijaya yang jadi wali. Ketika itu peperangan berlangsung dengan saudara, Raden Patah melawan Raden Husen. Sampai akhirnya musuh Majapahit kalah. Tapi tetap tidak masuk Islam sampai runtuhnya Negara.

Para wali tidak henti-hentinya menyebarluaskan agama Islam, sampai menggunakan media wayang. Dakwah melalui kesenian terus-menerus dijalankan. Jaka Tarub, salah satu wali memegang kedudukan di Demak. Raden Sarip Hidayat memegang kekuasaan di Cirebon.

\section{Edisi Teks Naskah Sejarah Cirebon}

Edisi teks merupakan bentuk suntingan yang sudah dibersihkan dari kesalahan-kesalahan. Kesalahankesalahan yang ditulis di tempat khusus yang disebut apparatus kritik. Selain dari itu, tanda-tanda khusus lainnya ada dalam edisi teks digunakan agar memudahkan bagi yang membaca.

Berkaitan dengan hal ini, transliterasi Naskah Sajarah Cirebon disesuaikan dengan ejaan yang disempurnakan. Menurut Baried dalam Putra (2016, kc. 197) menyebutkan bahwa cara kerja edisi teks standar yaitu membenarkan kesalahan dan ejaan sesuai dengan ejaan yang berlaku.

Setelah ditransliterasi, naskah Sejarah Cirebon disusun edisi teksnya serta ada beberapa kata yang diubah dan disesuaikan dengan ejaan. Kata-kata yang disesuaikan contohnya yaitu Aolia jadi aulia, Bagiyan jadi bagian, Buwana jadi buana, Duwa jadi dua, Isteri jadi istri, jst.

Serta ada beberapa tanda khusus yang digunakan dalam edisi teks, yang digunakan yaitu angka, tanda//, dan tanda (...).

1. Angka

Digunakan untuk menerangkan urutan pupuh, nomor baris, dan nomer halaman.

2. Tanda //

Tanda // ditulis sebelum nomor halaman. Cirinya bahwa itu halaman baru.

3. Tanda (...)

Digunakan untuk memberi tanda bahwa itu bacaan yang ditambahkan oleh penyunting.

\section{Nilai Moral dalam Naskah Sejarah Cirebon}

Nilai moral yang terdapat dalam naskah Sejarah Cirebon yaitu ada enam kategori nilai moral. Sesuai dengan acuan nilai moral dari Sudaryat $(2014$, kc. $125-$ 126) yaitu di bawah ini.

\section{Moral Manusia Terhadap Tuhan (MMT)}

Moral kepada Tuhan menggambarkan sikap dan perilaku manusia yang patuh dalam melaksanakan ajaran agama yang dianutnya, toleran terhadap pelaksanaan ibadah agama lain, serta hidup rukun dengan pemeluk agama lain. Nilai moral religius yang berkaitan dengan ketakwaan, dan kenyataan bahwa manusia lemah, jangan berputus asa, dan harus bisa menguasai diri. Dalam naskah ini menggambarkan beberapa tokoh yang taat terhadap Tuhannya. Diantaranya yaitu Pendeta Buda, Walangsungsang, Sarip Hidayat, Radén Sahid, dan lain sebagainya. Karakter tokoh dan tingkah laku yang diceritakan dalam naskah mengandung nilai-nilai moral manusia terhadap Tuhannya. Bagaimana caranya taat dan menjalankan ilmu agamanya, serta tergambar juga bagaimana sikap toleransi antara pendeta Buda dengan para calon wali yang memeluk agama Islam. Contoh bait yang mengandung 
nilai moral manusia pada tuhannya yaitu di bawah ini.

Ama sanggup ngadatangkeun putri
matur Radén Walangsungsang
bebendu ama sayaktos
jisim abdi tacan purun
gaduh bojo nanging abdi
ngimpi parantos patepung
sareng Kangjeng Rosul
//pisaur Kangjeng Nabi Muhammad
abdi kudu guru élmuning Nabi
sumangga atuh kang rama

Kutipan tersebut menggambarkan tokoh Walangsungsang yang belum ingin menikah, tapi ingin berguru ilmu Nabi, sebab bermimpi bertemu dengan Kanjeng Rosul. Serta mengajak ayahnya juga untuk nerguru agama. Hal ini menggambarkan Walangsungsang yang patuh terhadap petunjuk mengenai keagamaan.

\section{Moral Manusia Terhadap Pribadi (MMP)}

Moral manusia kepada dirinya merupakan sikap manusia dalam hubungannya dengan diri pribadi sebagai individu, yang ditandai dengan kualitas Sumber Daya Manusaia (SDM) atau Sumber Daya Insani (SDI). Nilai-nilai moral tentang manusia terhadap diri pribadi tercermin dari sifat-sifat (1) sopan, (2) sederhana, (3) jujur, (4) berani dan teguh pendirian dalam kebenaran dan keadilan, (5) bisa dipercaya, (6) menghormati dan menghargai orang lain, (7) waspada, (8) dapat mengendalikan diri, (9) adil dan berpikiran luas, (10) mencintai tanah air dan bangsa,serta (11) baik hati.

Dalam naskah ini banyak menceritakan tokoh-tokoh yang menggambarkan sikap yang kepribadiannya baik dan dapat dijadikan contoh. Bersikap sopan, sederhana, jujur, berani dan teguh, bisa dipercaya, hormat dan saling menghargai sesama, berhati-hati, bisa mengendalikan diri, adil dan luas cara berpikirnya, cinta tanah air dan bangsanya, baik hati dan ramah. Contoh yang menggambarkan sikap tersebut adalah Walangsaungsang Rarasantang dan Sarip Hidayat. Contoh bait naskah moral manusia terhadap pribadinya yaitu:

Turun gunung unggah gunung

henteu tuang henteu leueut

bawaning ku hayang tepang

jeung sadérék Radén Mantri

tunda heula nu angkat

kocapna dijero puri

Berdasarkan pada kutipan tersebut tergambar sikap Raden Mantri yang teguh dan tanggung jawab terhadap keinginan pribadinya dengan berani.

\section{Moral Manusia Terhadap Manusia Lainnya (MML)}

Moral manusia terhadap manusia lainnya yaitu merupakan sikap manusia dalam hubungannya dengan manusia lainnya dalam kehidupan bermasyarakat berbangsa dan bernegara yang ditandai dengan kesadaran akan adanya masyarakat yang multi-religi, multi-etnis, dan multi-kultur. Dalam naskah ini banyak tergambarkan mengenai sikapsikap baik dalam kehidupan bermasyarakat. Saling menyambut ketika bertemu, saling mendukung, serta saling bertukar ilmu pengetahuan. Hal ini banyak tergambarkan ketika Walangsungsang, Larasantang, dan Sarip Hidayat berkelana mengunjungi pendetapendeta dan tokoh lainnya. Serta disini banyak tergambar bagaimana caranya welas asih terhadap sesama meskipun berbeda etnis dan berbeda kepercayaan mereka tetap saling menghormati. Contoh bait naskah yang mengandung nilai manusia terhadap manusia lainnya yaitu di bawah ini.
Danuwarsih alon nyaur meugeus putra ulah nangis balik ieu kudu tampa ngaran Memenol Ali lélépén anu baheula 
kasiatna Déwi Sakti

Berdasarkan kutipan tersebut tergambar sikap manusia terhadap manusia lainnya, yang digambarkan oleh Danuwarsih yang membujuk agar tidak menangis terus dan memberinya jimat sakti.

\section{Moral Manusia Terhadap Alam (MMA)}

Moral manusia terhadap alam yaitu sikap manusia dalam hubungannya dengan lingkungan alam, ditandai dengan kesadaran ekologi/ekosistem dan geopolitik/kewilayahan. Sikap dan tindakan yang selalu berupaya mencegah kerusakan pada lingkungan alam di sekitarnya dan mengembangkan upayaupaya untuk memperbaiki kerusakan alam yang sudah terjadi. Dalam naskah ini ada beberapa gambaran sikap manusia yang baik perilakunya terhadap alam dan lingkungannya. Salah satunya ketika Walngsungsang akan membunuh bangau, dalam perangkap, tapi tidak jadi karena merasa kasihan terhadap bangau tersebut. Cntoh bait naskah yang mengandung nilai moral manusia terhadap alam yaitu di bawah ini.

Somaduloh nu dicatur deui
ayeuna keur ngadamel sawah
lega pisan sawahna téh
enggeus pirang-pirang taun
serta getoleun ameng tani
beurang peuting macul baé
paré patumpuk-tumpuk
diakutan ka bumina
henteu panjang nu dicatur lampah
tadi geus teu aya kakirangan
geunatipan

Berdasarkan kutipan tersebut tergambar sikap manusia hubungannya dengan lingkungan alam, Somaduloh yang medang membuat sawah dalam jangka tahunan, dan sawahnya luas sehingga hasilnyapun banyak.

\section{Moral ManusiaTerhadap Waktu (MMW)}

Moral manusia terhadap waktu yaitu merupakan sikap manusia dalam hubungannya dengan pemanfaatan waktu, ditandai dengan kesadaran yang akan adanya waktu linear, waktu cyclies, dan waktu baka. Manusia yang tidak menghargai waktu akan mendapatkan kerugian. Dalam naskah ini banyak menggambarkan tokoh-tokohnya yang menghargai waktu. Tergambar ketika menceritakan taatnya seorang petapa menunggu selesainya bertapa. Selama bertapa mereka tidak membuang waktu, tapi diisi oleh hal-hal yang positif. Ada yang bertani, ada yang mengasah ilmu, ada juga yang terus-terusan memuja terhadap Tuhannya. Contoh bait naskah yang mengandung nilai moral manusia terhadap waktu yaitu dibawah ini.
Asal Mekah pernah buyut Kangjeng
Rosul
di dinya keur tapa
reujeung ari lilana téh
dua ratus taun di dinya téh aya

Berdasarkan kutipan tersebut tergambar sikap setianya manusia terhada waktu, sampai rela menunggu dalam berpatanya selam dua ratus tahun.

\section{Moral Manusia Dalam Mengejar Kepuasan Lahiriah dan Batiniah (MMLB)}

Merupakan sikap dan perilaku manusia dalam memenuhi kebutuhan serta kepuasan lahir dan batin yang ditandai dengan kesadaran etika dan estetika. Jadi ada 2 nilai moral manusia dalam mengejar kepuasan, yakni moral manusia dalam mengejar kepuasan lahiriah dan mengejar kepuasan batiniah. Dalam naskah ini tergambar beberapa sikap dan perilaku tokohnya dalam mencapai kepuasannya sangat penuh perhitungan serta mengandung unsur etika dan estetika. Contohnya ketika mencapai kepuasan rumah tangga yang digambarkan oleh Raja Mesir dan Rarasantang, yang segala sesuatunya selalu dipasrahkan terhadap tuhannya. Serta selalu sopan santun dalam menjalankan hubungan dengan pasangannya. Contoh bait naskah yang 
mengandung nilai moral manusia dalam mencapi kepuasan lahiriah dan batiniahnya yaitu di bawah ini.

Sang pandita deui nyaur

jeung ieu bapa maparin

putra Bapa anggo garwa

anu ngaran Éndang Geulis

Walangsungsang enggus nikah

ka putra Pandita Sidik

Berdasarkan kutipan di atas tergambar adanya etika untuk mencapai kepuasan lahir batinnya yaitu dengan cara menikah.

\section{SIMPULAN}

Naskah Sejarah Cirebon yaitu naskah mengenai cerita para wali, naskah ini dari Aki Yahya Permana, ditulis dalam bahasa Sunda, aksara Pegon, serta menggunakan kertas pabrik ukuran 16,5 x 21,5x 2,5 $\mathrm{cm}$.Naskah Sejarah Cirebon merupakan salah satu judul dari sebuah naskah yang berbentuk buku. Keadaan naskahnya masih bisa terbaca normal, meskipun ada beberapa bagian yang sudah rusak.

Naskah Sejarah Cirebon isinya menceritakan mengenai perjalanan Walangsungsang dan Rarasantang dalam menyebarkan agama Islam, yang tidak diizinkan oleh bapaknya, Prabu Siliwangi. Perjalanan mencari ilmu agama dan mencari Nabi Muhammad diteruskan oleh putranya Rarasantang yang dikenal dengan nama Sarip Hidayat. Beliau berhasil menemukan syahadat sejati dan bertemu dengan Kanjeng Nabi Muhammad ketika Sarip Hidayat mi'roj serta diberi ilmu langsung mengenai ilmu agama. Sarip Hidayat mampu mengumpulkan para wali serta bekerja sama menyebarkan agama Islam di setiap Negara.

Dari hasil edisi teks Naskah Sejarah Cirebon, ditemukan beberapa kata yang disesuaikan dengan ejahan bahasa Sunda, serta berdasarkan pada Palangeran Éjahan Basa Sunda. Katakata yang diubah kebanyakannya kata yang memiliki dua suku kata biasanya ditambah dengan konsonan (y) dan (w), contohnya yang ada dalam naskah misalnya jariyah jadi jariah, tuwan jadi tuan.

Nilai moral yang ditemukan dalam Naskah Sejarah Cirebon yaitu Moral Manusia Terhadap Tuhan, Moral Manusia Terhadap Pribadi, Moral Manusia Terhadap Manusia Lainnya, Moral Manusia Terhadap Alam, Moral Manusia Terhadap Waktu, Moral Manusia Dalam Mengejar Kepuasan Lahiriah dan Batiniah.

Adapun nilai moral yang paling dominan yaitu nilai moral manusia terhadap Tuhannya, karena naskah sejarah Cirebon ini menceritakan mengenai perjalan para wali dalam menyebarkan agama Islam.

\section{DAPTAR PUSTAKA}

Antoni, Yoyok. 2016. Digitalisasi Naskah Kuno Dalam Upaya Pelestarian Dan Menarik Minat Generasi Muda. [e-jurnal] diakses di

http://unmasmataram.ac.id/wp/wco ntent/uploads/19.Bermansya-danYoyok-Antoni.pdf

Baried, S. B. (1985). Pengantar Teori Filologi. Jakarta: Pusat Pembinaan dan Pengembangan Bahasa Departemen Pendidikan dan Kebudayaan.

Fathurahman. O. (2015). Filologi Indonesia Teori dan Metode. Jakarta:Prenadamedia Group.

Isyanti, Dina. (2013). Prosiding Seminar Naskah Kuna Nusantara "Pangan dalam Naskah Kuna Nusantara”. Jakarta:Perpustakaan Nasional republik

KBBI (2007). Kamus Besar Bahasa Indonesia. Jakarta: Balai Pustaka.

Koswara, Dedi. (2013). Racikan Sastra Pangdeudeul Bahan Perkuliahan Sastra Sunda. Bandung: JPBD FPBS UPI. 
Noor, J. (2015). Metodologi Penelitian. Jakarta: Prenadamedia Group.

Purta, Afriyanda. 2016. Transliterasi dan Analis Teks Naskah "Sejarah Berdirinya Tarbiyah Islamiyah Karya Abdul Manaf. [e-jurnal] diakses di https://www.google.co.id/url?sa

Ratna, Ny. K. (2011). Teori, Metode, dan Teknik Penelitian Sastra. Yogyakarta: Pustaka Pelajar.

Ruhaliah. (2013). Wawacan Sebuah Genre Sastra Sunda. Bandung: JPBD FPBS UPI.
Said, Nur. (2016). Jurnal Ilmu Aqidah dan Studi Keagamaan. [e-jurnal] diakses di http://dx.doi.org/10.21043/fkrah.v4i $\underline{2.2084}$

Sudaryat, yayat. (2014). Wawasan Kasundaan. Bandung: JPBD UPI.

Suryani, E. (2010). Kearifan Budaya Sunda. Ciamis: Pemerintah Kabupaten Ciamis Dinas Kebudayaan dan Pariwisata Ciamis.

\section{UCAPAN TERIMA KASIH}

Terimakasih saya ucapkan kepada tim penyunting jurnal Lokabasa atas dipublikasikannya penelitian ini. 